\title{
First Principles Modelling of a Pasteurisation Plant for Model Predictive Control
}

\author{
MOHAMED T. KHADIR ${ }^{1,2}$ AND JOHN V. RINGWOOD ${ }^{2}$
}

\begin{abstract}
This paper investigates the physical modelling of an industrial pasteuriser plant from a control-oriented point of view. The investigated pasteuriser is based on plate heat exchangers (PHE) of type Clip 10-RM and brazed heat exchangers (BHE) of type CB76 from Alfa Laval. The traditionally highly complex and over parameterised models established for design, dimensioning, and scientific purposes are not suitable for use within a control strategy in their present form. In this paper, a simplified first order first principles (FP) model of the PHE sections as well as the BHE heaters constructing the pasteuriser are developed. An integrated model of the entire pasteuriser is then constructed combining the first principles model obtained for different pasteuriser components. The pasteuriser model parameters are identified, and the model is validated using data obtained during five test protocol sessions performed on an industrial process. Finally an example of a model predictive control (MPC) strategy, using the developed model, is briefly introduced. results are shown and conclusions are drawn.
\end{abstract}

Keywords: Milk pasteurisation, plate heat exchanger, brazed heat exchanger, first principles modelling, model predictive control.

\section{NOMENCLATURE}

A: Heat exchange area $\left(\mathrm{m}^{2}\right)$

$C_{p}: \quad$ Milk specific heat coefficient $(\mathrm{j} / \mathrm{kg} / \mathrm{K})$

$C_{m}:$ Water specific heat coefficient $(\mathrm{j} / \mathrm{kg} / \mathrm{K})$

$F_{p}$ : Product flow rate $\left(\mathrm{m}^{3} / \mathrm{h}\right)$

$F_{m}$ : Medium flow rate $\left(\mathrm{m}^{3} / \mathrm{h}\right)$

$H$ : Coincidence point equal to unity

$K_{p a}$ : Thermal conductivity of the wall $\mathrm{W} /(\mathrm{m} \mathrm{k})$

$Q$ : Total heat flow (W)

$s_{w}$ : Thickness of the wall (m)

$T_{i p}$ : Input temperature of the fluid product $\left({ }^{\circ} \mathrm{C}\right)$

\footnotetext{
${ }^{t}$ Address correspondence to: Tarek Khadir, Department of Electronic Engineering, NUI Maynooth, Co. Kildare. Ireland. E-mail: tarek.khadir@eeng.may.ie

${ }^{2}$ Department of Electronic Engineering, NUI Maynooth, Co. Kildare, Ireland.
} 
$T_{\text {im }}$ : Input temperature of the fluid medium $\left({ }^{\circ} \mathrm{C}\right)$

$T_{s m}$ : Output temperature of the fluid medium $\left({ }^{\circ} \mathrm{C}\right)$

$T_{s p}$ : Output temperature of the fluid product $\left({ }^{\circ} \mathrm{C}\right)$

$T_{p a}$ : Plate temperature $\left({ }^{\circ} \mathrm{C}\right.$ )

$T_{w p}:$ Temperature of the product film $\left({ }^{\circ} \mathrm{C}\right)$

$T_{\mathrm{w} m}$ : Temperature of the medium film $\left({ }^{\circ} \mathrm{C}\right)$

$U: \quad$ Total heat transfer coefficient $\left(\mathrm{W} / \mathrm{m}^{2} / \mathrm{K}\right)$

$U_{m}$ : Heat transfer coefficient plate/medium $\left(\mathrm{W} / \mathrm{m}^{2} / \mathrm{K}\right)$

$U_{p}$ : Heat transfer coefficient plate/product $\left(\mathrm{W} / \mathrm{m}^{2} / \mathrm{K}\right)$

$V_{p}$ : Volume of the product area $\left(\mathrm{m}^{3}\right)$

$V_{m}$ : Volume of the medium area $\left(\mathrm{m}^{3}\right)$

$\rho_{p}: \quad$ Product density $\left(\mathrm{kg} / \mathrm{m}^{3}\right)$

$\rho_{m}: \quad$ Medium density $\left(\mathrm{kg} / \mathrm{m}^{3}\right)$

\section{INTRODUCTION}

Predictive control is becoming a valuable control strategy for higher control requirements that is tighter, faster regulation or tracking in the industrial world. MPC has been used in over 2,000 industrial applications including refining, petrochemical, chemical, pulp and paper and food processing industries [1]. Most of these algorithms rely on a linear or linearised internal model. First principles modelling is highly regarded in the control engineering community as its parameters usually have a physical meaning, which strongly relates parameter identification to the physical process. In this case, any physical changes are easily interpreted in the model, involving usually a change of a given parameter value, giving FP models a generalisation feature that black-box models do not have. However FP models developed for control purposes have to be valid, at least within an operative region, without being too complex and over-parameterised.

Before starting on the mathematical modelling of the pasteuriser leading to a set of differential equations, a thorough understanding of the physical process has to be completed. In the next section, a description of the pasteuriser plant used for this study is presented.

\section{PHYSICAL DESCRIPTION OF THE PASTEURISER}

The pasteuriser used is based on a Clip 10-RM plate heat exchanger (PHE) [2] and brazed heat exchangers (BHE), A PHE consists of a pack of stainless steel plates clamped in a frame. The plates are corrugated in a pattern designed to increase the flow turbulence of the medium and the product. The pasteuriser is divided into five sections, S1 to S5. Section S4 and S2 are for regeneration, S1 and S3 for heating and 


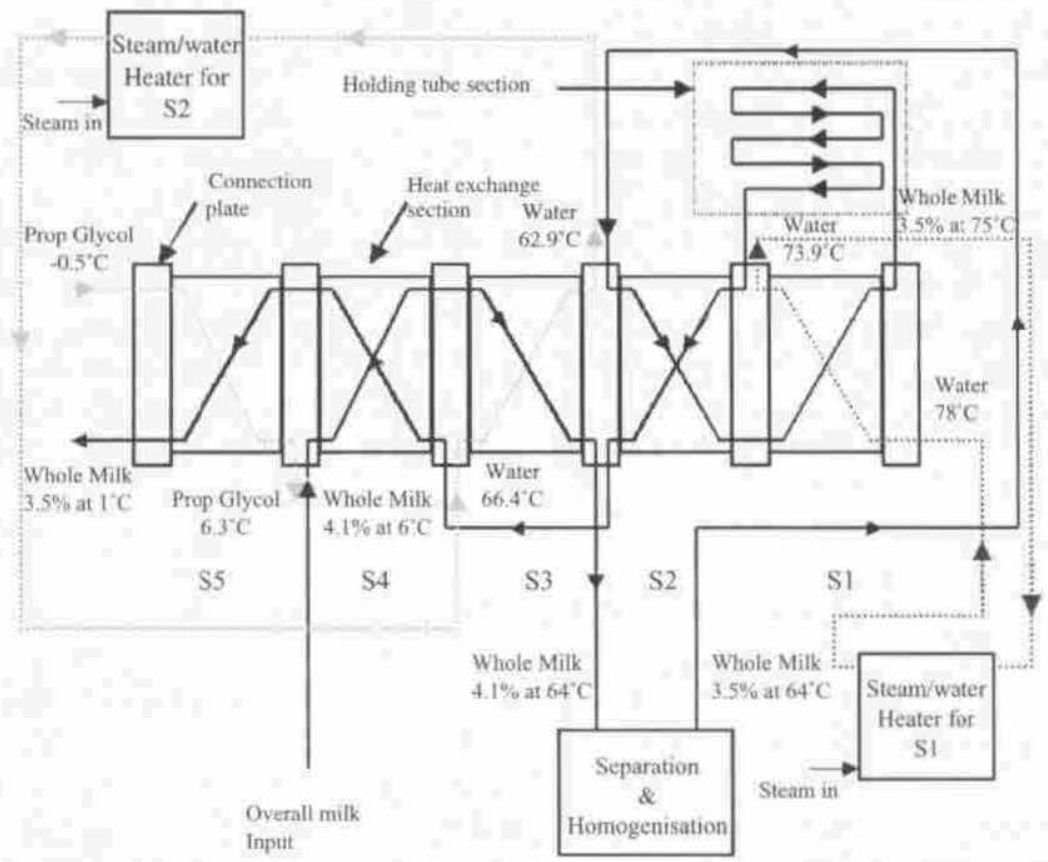

Fig. 1, General layout of the pasteuriser.

S5 for cooling (see Fig. 1). The BHEs are used to heat the water used as a heating medium in the PHE. The heating surface in a BHE consists of thin corrugated metal plates stacked on top of each other. Channels are formed between the plates and corner ports are arranged so that the flow media flows through alternate channels always in counter-current flow. The media and product are kept in the unit by a brazed seal around the edge of the plates. The contact points of the plates are also brazed to withstand the pressure of the media handled.

The pasteuriser operates as follow: Firstly, the raw milk at a concentration of $4.1 \%$ enters section $\mathrm{S} 4$ of the $\mathrm{PHE}$ at a temperature of $2.0^{\circ} \mathrm{C}$. It is then preheated to a temperature of $60.5^{\circ} \mathrm{C}$ by the outgoing pasteurised milk which as a result is reduced to a temperature of $11.5^{\circ} \mathrm{C}$. Passing this section, the milk now at a temperature of $60.5^{\circ} \mathrm{C}$, enters section $\mathrm{S} 3$ where its temperature increases to $64.5^{\circ} \mathrm{C}$ using hot water as a medium. The milk, before reaching the next section, is first separated from the fat then standardised and homogenised to a concentration of $3.5 \%$. It then enters section $\mathrm{S} 2$, where it is preheated to a temperature of $72^{\circ} \mathrm{C}$ using the already pasteurised milk as a medium. The milk is finally brought to the pasteurisation temperature in section S1 $\left(75.0^{\circ} \mathrm{C}\right)$ using hot water at around $77.0^{\circ} \mathrm{C}$ as a medium. After that the 
homogenised pasteurised milk is held at the pasteurisation temperature for $15 \mathrm{~s}$ in the holding tube section before being cooled using the incoming cold milk in section S4 and section S2. Finally, the pasteurised milk enters the cooling section (section S5) at a temperature of $11.5^{\circ} \mathrm{C}$, where the milk is chilled to a temperature of $1.0^{\circ} \mathrm{C}$ using propylene glycol as a medium at a temperature of $-0.5^{\circ} \mathrm{C}$. Note that the water for the heating sections S3 and S4 is brought to the adequate temperature in steam/water heaters of type CB76 from Alfa Laval. As shown in Figure 1, milk pasteurisation temperature is a function of three inputs: steam flow injected in steam/water heater 1, steam flow injected in steam/water heater 2 and the milk input temperature, defined as $F_{v 1}, F_{v 2}$ and $T_{i m}$, respectively, or can be function of the output temperature at section S3 and the steam flow $F_{v 1}$. Note that the steam temperature is constant and have a value of $110.0^{\circ} \mathrm{C}$.

\section{FIRST PRINCIPLES MODELLING OF THE PHE}

Modelling of PHEs has been extensively researched since the early 1920s when PHEs started to be used in the dairy industry [3]. However, most research efforts have been directed towards establishing models in order to design PHEs (i.e., dimensioning, shape, etc.) $[4,5]$. The literature featuring such research is rich. For example, Thonon $[6,7]$ studied extensively the dimensioning of PHE's and their hydraulic and heat performances as a part of his $\mathrm{Ph} . \mathrm{D}$. studies. Similar research concerning hydraulic performances can be found in [8, 9]. Another article by Thonon and Mercier, [10] deals with dimensioning and distribution problems in PHEs, which is also investigated in [11-13]. Most of these models concern dimensioning, are over parameterised and investigate primarily the steady state characteristics of the PHEs.

The first attempt to dynamically model PHEs was conducted by Wolf in [14], where heat transfer between streams in a heat exchanger is described by a system of first order differential equations. The model was reviewed in [15] considering only relatively simple problems. Later, Morano and Jechura in [16] proposed a computer implementation of the differential equations describing heat transfer, based on the eigenvalues and eigenvectors of the system.

More sophisticated models have been developed since, for instance the so-called "cinematic" model developed by Lakshmanan and Potter, [17]. In this model, the effect of the plate is neglected and the exchange in every channel (between two plates) is described by a differential equation. This leads to an $n$ by $n$ system, where $n$ is the number of channels. In the same way, a more complex representation based on a dispersion model is given by Roetzel and Das [18]. An extensive analysis based on the same approach is given in [19]. First principles models developed in [17-19] consider the differential equations describing heat exchange in every channel (i.e., between two plates). This leads to a relatively large 
number of equations (i.e., equal to the number of channels) and does not give the final output product or medium temperature. Such models are not suitable for implementation in model based controllers because of their relative complexity providing an appreciable, but not useful, level of detail for a model based control scheme. As far as prediction for control purposes is concerned, the modelling objectives are a model that is able to predict future output temperatures, while keeping a conservative complexity level in order to allow implementation. The modelling approach used in this paper aims to produce a simple model, yet with an appreciable level of detail. The first principles model is based on the energy balance equations of the heat transfer process, and considers every section of the PHE as a single plate, where the fluids, product and medium, pass at either side (for heat transfer through a wall see Section 3.1). Such a model, if validated, will provide the temperature evolution of both product and medium as a function of their input temperatures and flows. The models for each section are then concatenated in order to give the full PHE model.

The thermal evolution of the product (milk) and the medium (milk in preheating sections, or water in heating sections) is evaluated under the following assumptions:

- every fluid is ideally mixed in the direction of flow,

- the heat conduction in the flow direction is negligible,

- the heat is only transferred in one direction, perpendicular to the flow axis,

- the effect of temperature on the specific heat and density of each fluid is negligible,

- there are no phase changes during the heat transfer (including no fouling), and

- thermal losses are neglected.

\subsection{Heat Transfer Through a Wall}

Before starting the mathematical analysis of the PHE, let us first emphasise the notion of heat exchange through a wall or plate. The phenomenon is illustrated in Figure 2. Both medium and product flow at each side of the plate in opposite directions (counter-current flow). A thin film of product and medium tends to be created at each side along the wall. In the case of heating a product by a medium, the medium temperature decreases, both spatially and over time, until reaching virtually the temperature of the medium's thin film. On the product side, the product temperature increases to reach the temperature of the product's thin film. This notion of heat transfer through a wall can be found in nearly all books dealing with heat transfer for example [20].

The overall heat flow, $Q$, between product and medium input temperatures, $T_{i m}$ and $T_{i p}$ respectively, is given by Equation (1), as:

$$
Q=A U\left(T_{i p}-T_{i m}\right)
$$




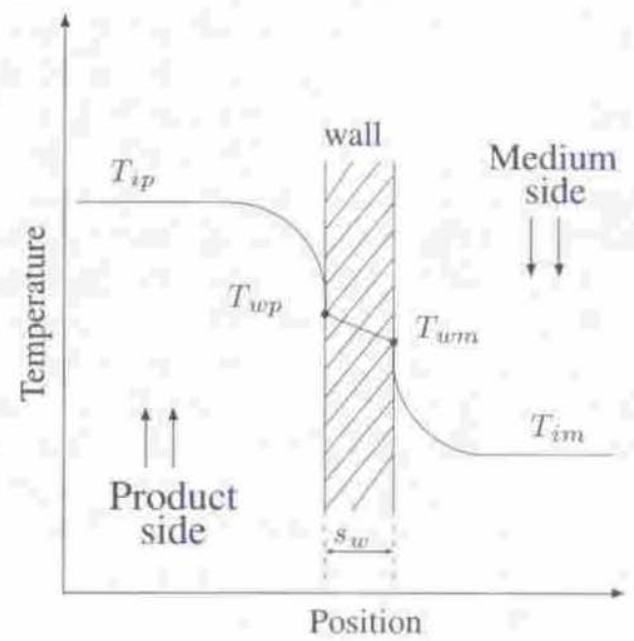

Fig. 2. Heat transfer through a wall.

Respecting the heat conservation principle, the same heat flow between different media can be given by Equations (2)-(4):

- heat flow between the product input temperature, $T_{i p}$, and the thin film's temperature on the product side, $T_{w p}$.

$$
Q=A U_{p}\left(T_{i p}-T_{w p}\right)
$$

- heat flow between the thin film's temperature on the medium side, $T_{m p}$ and the medium's input temperature, $T_{i m}$.

$$
Q=A U_{m}\left(T_{w m}-T_{\text {im }}\right)
$$

- heat flow across the wall, or heat flow between the thin film's temperature on the medium side, $T_{w m}$, and the thin film's temperature on the product side, $T_{w p}$.

$$
Q=A \frac{K_{p a}}{s_{w}}\left(T_{w p}-T_{w m}\right)
$$

To obtain the temperature of the films on both sides of the plate, we equalise Equations (1) and (2) as well as Equations (1) and (3). The resulting $T_{w p}$ and $T_{w m}$ are given in Equations (5) and (6). The steady state films temperatures $T_{w p}$ and $T_{w m}$, are important as they will be used in further development (Section 3.2).

$$
\begin{aligned}
T_{w p} & =T_{i p}-\frac{U}{U_{p}}\left(T_{i p}-T_{i m}\right) \\
T_{w m} & =T_{i m}+\frac{U}{U_{m}}\left(T_{i p}-T_{i m i}\right)
\end{aligned}
$$




\subsection{Heat Transfer in Every Section of the PHE}

Considering each section of the PHE as a heat transfer problem between two fluids separated by a plate, the heat transfer evolution can be then characterised by the energy balance Equations (7)-(9), for the product, medium and plate, respectively.

\section{Product side}

$$
\rho_{p} C_{p} V_{p} \frac{d T_{o p}(t)}{d t}=\rho_{p} C_{p} F_{p}\left(T_{i p}(t)-T_{o p}(t)\right)+U_{p} A\left(T_{p a}(t)-T_{o p}(t)\right)
$$

\section{Medium side}

$$
\rho_{m} C_{m} V_{m} \frac{d T_{a m}(t)}{d t}=\rho_{m} C_{m} F_{m}\left(T_{i m}(t)-T_{o m}(t)\right)+U_{m} A\left(T_{p a}(t)-T_{m m}(t)\right)
$$

Plate

$$
\rho_{p a} C_{p a} V_{p a} \frac{d T_{p a}(t)}{d t}=U_{m} A\left(T_{o p}(t)-T_{p a}(t)\right)+U_{p} A\left(T_{a m}(t)-T_{p a}(t)\right)
$$

Rearranging Equations (7)-(9) in order to group factors multiplied with similar temperatures, we obtain:

\section{Product side}

$$
\rho_{p} C_{p} V_{p} \frac{d T_{o p}(t)}{d t}=\rho_{p} C_{p} F_{p} T_{i p}(t)-\left(\rho_{p} C_{p} F_{p}+U_{p} A\right) T_{o p}(t)+U_{p} A T_{p a}(t)
$$

\section{Medium side}

$$
\rho_{m} C_{m} V_{m} \frac{d T_{o m}(t)}{d t}=\rho_{m} C_{m} F_{m} T_{i m}(t)-\left(\rho_{m} C_{m} F_{m}+U_{m} A\right) T_{o m}(t)+U_{m} A T_{p a}(t)
$$

Plate

$$
\rho_{p a} C_{p a} V_{p a} \frac{d T_{p a}(t)}{d t}=U_{m} A T_{a p}(t)-\left(U_{m} A+U_{p} A\right) T_{p a}(t)+U_{p} A T_{o m}(t)
$$

For the sake of simplification the following notation is used:

$$
\begin{aligned}
\tau_{1}=\frac{\rho_{p} C_{p} V_{p}}{\rho_{p} C_{p} F_{p}+U_{p} A}, & \lambda_{1}=\frac{\rho_{p} C_{p} F_{p}}{\rho_{p} C_{p} F_{p}+U_{p} A} \\
\tau_{2}=\frac{\rho_{m} C_{m} V_{m}}{\rho_{m} C_{m} F_{m}+U_{m} A}, & \lambda_{2}=\frac{\rho_{m} C_{m} F_{m}}{\rho_{m} C_{m} F_{m}+U_{m} A} \\
\tau_{3}=\frac{\rho_{p a} C_{p a} V_{p a}}{U_{m} A+U_{p a} A}, & \lambda_{3}=\frac{U_{p} A}{U_{m} A+U_{p} A}
\end{aligned}
$$


This notation leads to the following simplified equations:

\section{Product side}

$$
\tau_{1} \frac{d T_{o p}(t)}{d t}+T_{o p}(t)=\lambda_{1} T_{i p}(t)+\left(1-\lambda_{1}\right) T_{p a}(t)
$$

Medium side

$$
\tau_{2} \frac{d T_{o m}(t)}{d t}+T_{o m}(t)=\lambda_{2} T_{i m}(t)+\left(1-\lambda_{2}\right) T_{p a}(t)
$$

Plate

$$
\tau_{3} \frac{d T_{p a}(t)}{d t}+T_{p a}(t)=\lambda_{3} T_{o p}(t)+\left(1-\lambda_{3}\right) T_{o m}(t)
$$

Note that the plate's temperature is a function of both fluid temperatures at each side. Therefore, its temperature is not uniform and equal through all its thickness. However, the plate dynamics $\left(\rho_{p a} C_{p a} V_{p a}\right)$ are faster than the fluid ones, due principally to:

- the plate's low specific heat coefficient, $C_{p a}=872.5 \mathrm{~J} \mathrm{~kg}^{-1} \mathrm{~K}^{-1}$ for stainless steel, while for water and milk the specific heat coefficients are $C_{m}=4200 \mathrm{Jkg}^{-1} \mathrm{~K}^{-1}$, $C_{p}=3800 \mathrm{~J} \mathrm{~kg}^{-1} \mathrm{~K}^{-1}$, respectively, and

- the fact that the plate thickness is sensibly thinner than the thickness of the space between two plates, space allocated to the liquids (i.e., plate thickness $s=0.5 \mathrm{~mm}$, while distance between two plates is between $4-5 \mathrm{~cm}$ ). Therefore, the plate's volume $V_{p a}$ is sensibly smaller than the volume of the product or medium $V_{m}$ and $V_{p}$, respectively.

For these two reasons, the plate temperature in Equations (13) and (14) can be replaced by the steady state temperature of the plate's sides. Now, as thin films are created on each of its sides (see Section 3.1), the plate temperature at each side can be approximated by respective thin film temperature. In Equation (13) it comes to replace $T_{p a}$, the plate temperature, by $T_{w p}$ the temperature of the film on the product side given in Equation (5), and $T_{p a}$ in Equation (14) by $T_{w m}$ the temperature of the film on the medium side given in Equation (6).

\section{Product temperature evolution}

$$
\tau_{1} \frac{d T_{o p}(t)}{d t}+T_{o p}(t)=\lambda_{1} T_{i p}(t)+\left(1-\lambda_{1}\right)\left(T_{i p}(t)-\frac{U}{U_{p}}\left(T_{i p}(t)-T_{i m}(t)\right)\right)
$$

Medium temperature evolution

$$
\tau_{2} \frac{d T_{i m}(t)}{d t}+T_{o m}(t)=\lambda_{2} T_{i m}(t)+\left(1-\lambda_{2}\right)\left(T_{i m}(t)+\frac{U}{U_{m}}\left(T_{i p}(t)-T_{i m}(t)\right)\right)
$$


After developing Equations (16) and (17) in order to group terms in $T_{i p}$ and $T_{i m}$, we obtain the following equation:

$$
\begin{aligned}
T_{1} \frac{d T_{o p}(t)}{d t}+T_{o p}(t) & =\left(1-\frac{U}{U_{p}}\left(1-\lambda_{1}\right)\right) T_{i p}(t)+\frac{U}{U_{p}}\left(1-\lambda_{1}\right) T_{i m}(t) \\
\tau_{2} \frac{d T_{o m}(t)}{d t}+T_{o m}(t) & =\left(1-\frac{U}{U_{m}}\left(1-\lambda_{2}\right)\right) T_{i m}(t)+\frac{U}{U_{m}}\left(1-\lambda_{2}\right) T_{i p}(t)
\end{aligned}
$$

For the sake of simplification the following notations are adopted:

$$
\begin{array}{ll}
\tau_{p}=\tau_{1}, & \lambda_{p}=1-\frac{U}{U_{p}}\left(1-\lambda_{1}\right) \\
\tau_{m}=\tau_{2}, & \lambda_{m}=1-\frac{U}{U_{m}}\left(1-\lambda_{2}\right)
\end{array}
$$

Finally, the output temperature of the product $T_{o p}$ and the medium $T_{i m}$ are functions of the input temperature of both medium and product only, given in Equations (20) and $(21)$ as:

$$
\begin{aligned}
\tau_{p} \frac{d T_{o p}(t)}{d t}+T_{o p}(t) & =\lambda_{p} T_{i p}(t)+\left(1-\lambda_{p}\right) T_{i m}(t) \\
\tau_{m} \frac{d T_{o m}(t)}{d t}+T_{o m}(t) & =\lambda_{m} T_{i m}(t)+\left(1-\lambda_{m}\right) T_{i p}(t)
\end{aligned}
$$

\section{FIRST PRINCIPLES MODELLING OF THE BHE}

The medium (water) used to heat the milk in sections S1 and S3 has to be heated to an appropriate temperature before being routed into the PHE (see Fig. 1). This is performed in two brazed heat exchangers (BHE) of type CB76 described in Section 2. The water then becomes the product to heat using hot steam at $110.0^{\circ} \mathrm{C}$. In order to establish a model for the CB76 unit the following assumptions are considered:

- the total steam energy is transmitted to the plate, and is then transmitted to the product (water),

- the full amount of steam injected is condensed on the plate,

- the steam temperature is constant $\left(110^{\circ} \mathrm{C}\right)$, making the steaming heat value $(l)$ constant, and

- losses are neglected. 
Note that in the BHEs the water plays the role of the product, heated by steam as a medium. However, the product output temperature is still referred to as medium input temperature, $T_{i m}$ (medium temperature at the entrance of the PHE), in order to avoid any possible confusion. Similarly, $T_{o m}$ is the temperature of the water at the exit of the PHE and therefore, the temperature of the water entering the BHE. Taking the above into consideration, we obtain the following energy balance equations:

\section{Water side}

$$
\rho_{m} C_{m} V_{m} \frac{d T_{i m}(t)}{d t}=\rho_{m} C_{m} F_{m}\left(T_{o m}(t)-T_{i m}(t)\right)+U_{p} A\left(T_{p a}(t)-T_{i m}(t)\right)
$$

\section{Steam side}

$$
\rho_{p a} C_{p a} V_{p a} \frac{d T_{p a}(t)}{d t}=U_{p a} A\left(T_{i m}(t)-T_{p a}(t)\right)+I F_{s}(t)
$$

Rearranging Equations (22) and (23) in order to group similar terms:

\section{Water side}

$$
\rho_{m} C_{m} V_{m} \frac{d T_{i m}(t)}{d t}=\rho_{m} C_{m} F_{m} T_{o m}(t)-\left(\rho_{m} C_{m} F_{m}+U_{p} A\right) T_{i m}(t)+U_{p} A T_{p a}(t)
$$

\section{Steam side}

$$
\rho_{p a} C_{p a} V_{p a} \frac{d T_{p a}(t)}{d t}=U_{p a} A T_{i m}(t)-U_{p a} A T_{p a}(t)+I F_{s}(t)
$$

For simplification reasons, let us adopt the following notations:

$$
\begin{array}{cc}
\tau_{i m}=\frac{\rho_{m} C_{m} V_{m}}{\rho_{m} C_{m} F_{m}+U_{m} A}, & \lambda_{i m}=\frac{\rho_{m} C_{m} F_{m}}{\rho_{m} C_{m} F_{m}+U_{m} A} \\
\tau_{p a}=\frac{\rho_{p a} C_{p a} V_{p a}}{U_{p a} A}, & \lambda_{p a}=\frac{l}{U_{p a} A}
\end{array}
$$

Replacing $\tau_{i m}, \lambda_{i m}, \tau_{p a}$ and $\lambda_{p a}$ in (24) and (25), finally, we obtain the following differential equations:

\section{Water side}

$$
\tau_{i m} \frac{d T_{i m}(t)}{d t}+T_{i m}(t)=\lambda_{i m} T_{a m}(t)+\left(1-\lambda_{i m}\right) T_{p a}(t)
$$

\section{Steam side}

$$
\tau_{p a} \frac{d T_{p a}(t)}{d t}+T_{p a}(t)=T_{i m}(t)+\lambda_{p a} F_{s}(t)
$$


It can be seen that the PHE model Equations (20) and (21), and the BHE model Equations (26) and (27) that the final difference equations are consistent in form. Indeed, the product output temperature is always contained between the input medium temperature and the input product temperature.

\section{INTEGRATED PASTEURISER MODEL}

The complete pasteuriser is constituted from a combination of PHE sections and two BHEs heaters for heating the milk and the water respectively. As shown in Figure 1, section $\mathrm{S} 3$ of the PHE is connected to BHE1 and section $\mathrm{S} 1$ is connected to BHE2. In what follows, the coupled system BHE-PHE shown in Figure 3, is detailed and expressed as a set of differential equations.

\subsection{Description of the Coupled System PHE-BHE}

The coupled system can be described by coupling Equations (20), (21), (26) and (27). The input water temperature $T_{i m}$, a function of $F_{v}$, for sections $\mathrm{S} 1$ and $\mathrm{S} 3$ is given by Equations (26) and (27), while the milk output temperature $T_{o p}$, a function of $T_{i m}$, is given in Equations (20) and (21). The milk output temperature can then be given by a combination of the four cited equations, where the manipulated variable is the steam flow $F_{\mathrm{y}}$ at the $\mathrm{BHE}$ input, and the disturbance variable is the PHE input milk temperature $T_{i m}$.

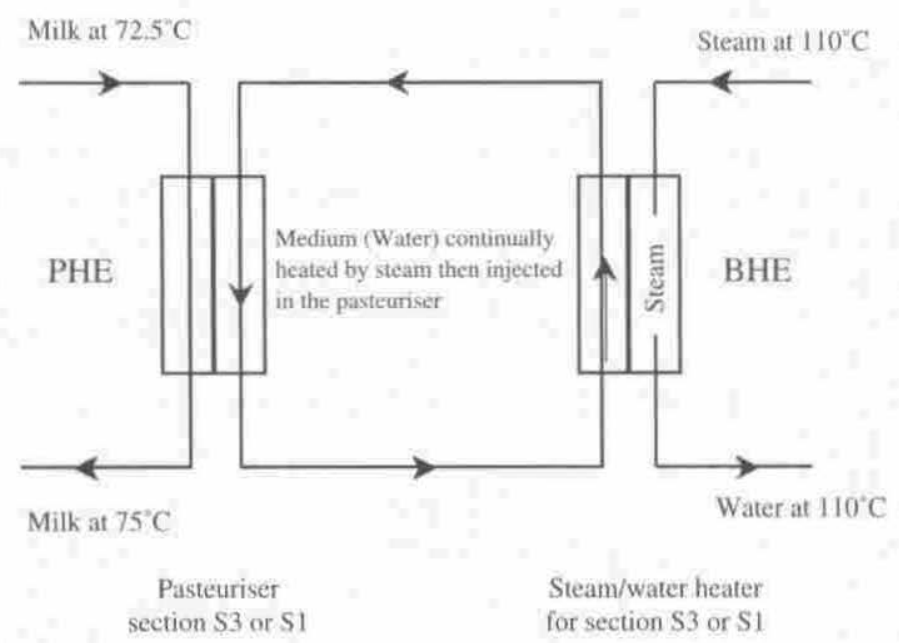

Fig. 3. Block diagram of the coupled system. 


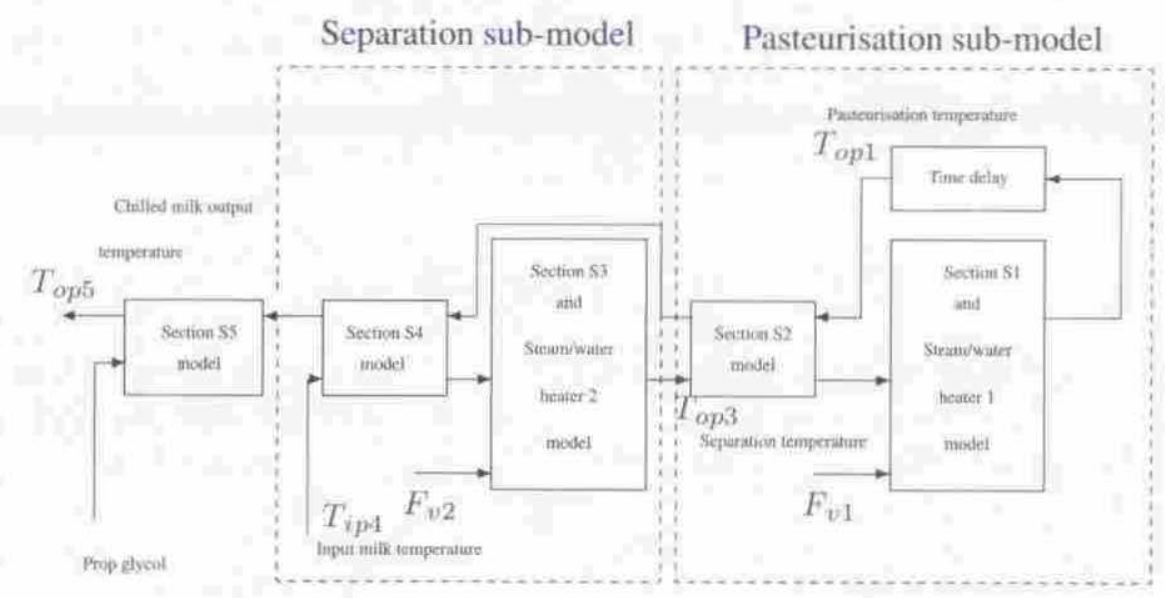

Fig. 4. Overall pasteuriser model.

\subsection{Complete Mathematical Model}

The complete pasteurisation plant model, for temperature variables represented by the block diagram in Figure 4 is constructed by putting in cascade:

- a PHE model for section S5,

- a PHE model for section S4,

- a coupled model for PHE section S3 and BHE2,

- a PHE model for section S2, and

- a coupled model for PHE's section S1 and BHE1,

Keeping in mind the modelling objectives (i.e., temperature control) and the available instrumentation of the plant [21], the overall plant model can be divided into two sub-models. One sub-model is for the pasteurisation temperature $\left(T_{\text {op } 1}\right)$ as a function of the output temperature at section $\mathrm{S} 3\left(T_{o p 3}\right)$ and steam flow in BHE1 $\left(F_{\mathrm{v} 1}\right)$. The other sub-model gives the separation temperature $\left(T_{o p 3}\right)$ as a function of the output temperature at section S1 $\left(T_{o p 1}\right)$, the steam flow in BHE2 $\left(F_{v 2}\right)$ and the milk input temperature at section $\$ 4\left(T_{i p 4}\right)$, as shown in Figure 4.

Dividing the overall model into two sub-models seems to be appropriate for the following reasons:

- The plant instrumentation is designed to permit a control scheme dividing the plant into three control problems (i.e., pasteurisation, separation and cooling).

- Using a compact model will reduce possible model mismatch (i.e., the more complicated the model is, the greater the possibility of mismatches between plant and model). 
In what follows, the cooling section is not considered as the prime objective of the paper is to provide a model for an MPC control strategy for the pasteurisation and separation temperature in order to improve the existing control performance.

The pasteurisation sub-model is given as a combination of Equations (26) to (27) for the BHEs and Equations (20) and (21) for the PHE sections S2 and S1. The pasteurisation sub-model can then be giving by the following state space equation.

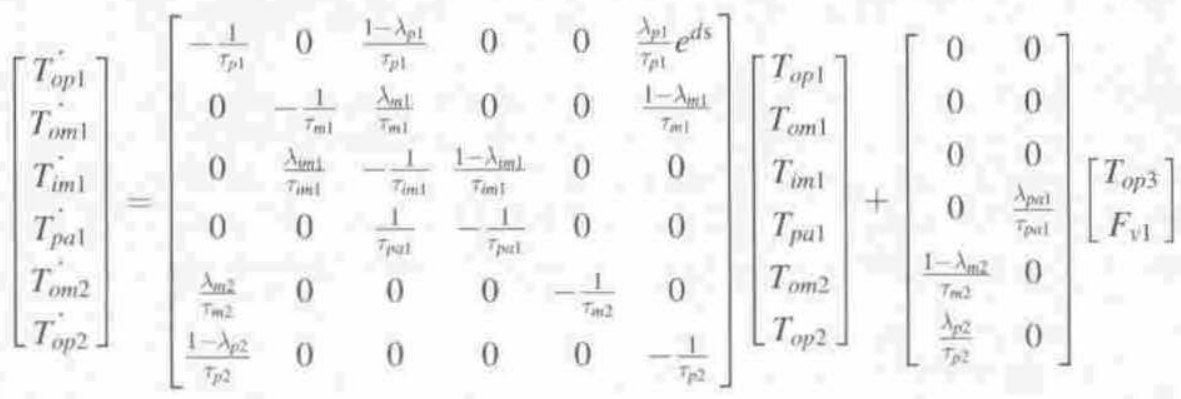

where the system output $y$ is the pasteurisation temperature $T_{\text {cpl }}$, given in Equation (29).

$$
y=\left[\begin{array}{llllll}
1 & 0 & 0 & 0 & 0 & 0
\end{array}\right]\left[\begin{array}{llllll}
T_{o p 1} & T_{o m 1} & T_{i m 1} & T_{p a 1} & T_{o m 2} & T_{o p 2}
\end{array}\right]^{T}
$$

Following a similar construction, a state-space representation of the separation submodel is given by the state space system Equations (30) and (31):

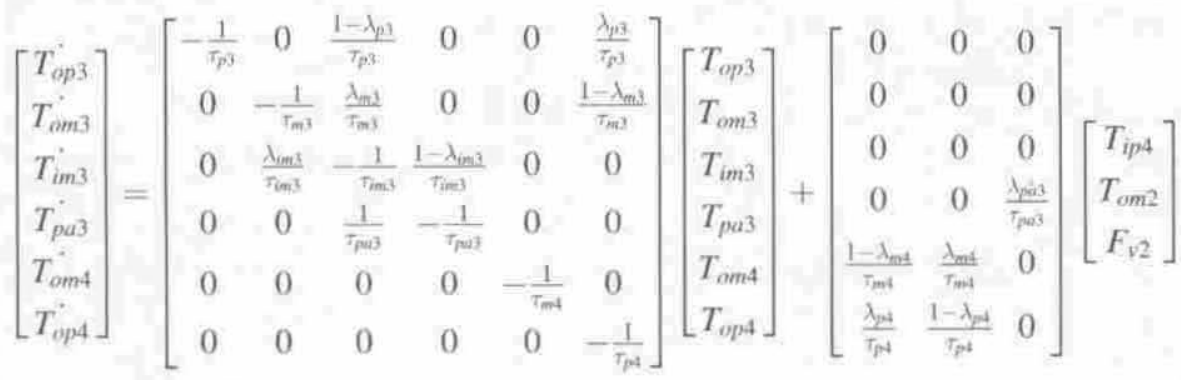

where the system output $y$ is the pasteurisation temperature $T_{o p 3}$, given in Equation (31).

$$
y=\left[\begin{array}{llllll}
1 & 0 & 0 & 0 & 0 & 0
\end{array}\right]\left[\begin{array}{llllll}
T_{o p 3} & T_{a m 3} & T_{i m 3} & T_{p a 3} & T_{o m 4} & T_{o p 4}
\end{array}\right]^{T}
$$

The state space form is useful in highlighting the interactions between different variables in the system. For example, it can be seen from Equation (28) how $T_{o p 3}$, the 
separation output milk temperature, appears in the pasteurisation sub-model as the milk input temperature. In the same manner, $T_{o p 1}$ the pasteurisation output milk temperature, appears as the medium input temperature in the separation sub-model Equation (30).

\section{PARAMETER IDENTIFICATION AND MODEL VALIDATION}

Prior to any industrial use of the model established earlier, it is necessary to ensure that it effectively has the same behavior as the physical process. This is investigated within the validation phase. In order to perform a meaningful model validation. informative data must be collected. This means that a test protocol has to be applied to the physical process in order to extract the output responses needed.

\subsection{Test Protocol and Available Data}

We were generously allowed five sessions for data collection from the plant management, each of approximately $4-5 \mathrm{~h}$ long, which is the maximum period for which a second smaller pasteuriser can keep production going. During the testing we were allowed to vary the steam flow valves around their normal operative points in order to provoke changes around the nominal output separation and pasteurisation temperatures (i.e., $64.0^{\circ} \mathrm{C}$ and $75.0^{\circ} \mathrm{C}$ ). The plant responses for five test protocols have been concatenated and are given in Figure 5. It can be seen that the changes provoked range between $55.0^{\circ} \mathrm{C}$ to $85.0^{\circ} \mathrm{C}$ for pasteurisation temperature $\left(T_{o p 1}\right)$ and, $50.0^{\circ} \mathrm{C}$ to $74.0^{\circ} \mathrm{C}$ for the separation temperature $\left(T_{o p 3}\right)$.

Clearly the process rise time is greater than $30 \mathrm{~min}(1800 \mathrm{~s})$. Thus a sampling period $T_{s}$ of $12 \mathrm{~s}$ was found to be more economical than $1 \mathrm{~s}$, and still satisfies the usual Shannon sampling theorems [22] as well as sampling requirements for industrial processes given by Equation (32) [23].

$$
T_{s}=\frac{T_{r}}{N}, \quad \text { with } 30<N<50
$$

where $T_{r}$ is the process rise time at $63 \%$, and $N$ a constant.

\subsection{Parameter Identification}

In order to have a manageable model, the model's parameters are chosen to be the $\lambda$ 's and $\tau$ 's found in the two subsystems given in Equations (28) and (30). Temperature measurement at the output of sections S4 and S2 are not available. The parameters related to these sections were initially enumerated based on the characteristics of the materials and media (e.g., specific heat coefficient, density, etc.), the physical 


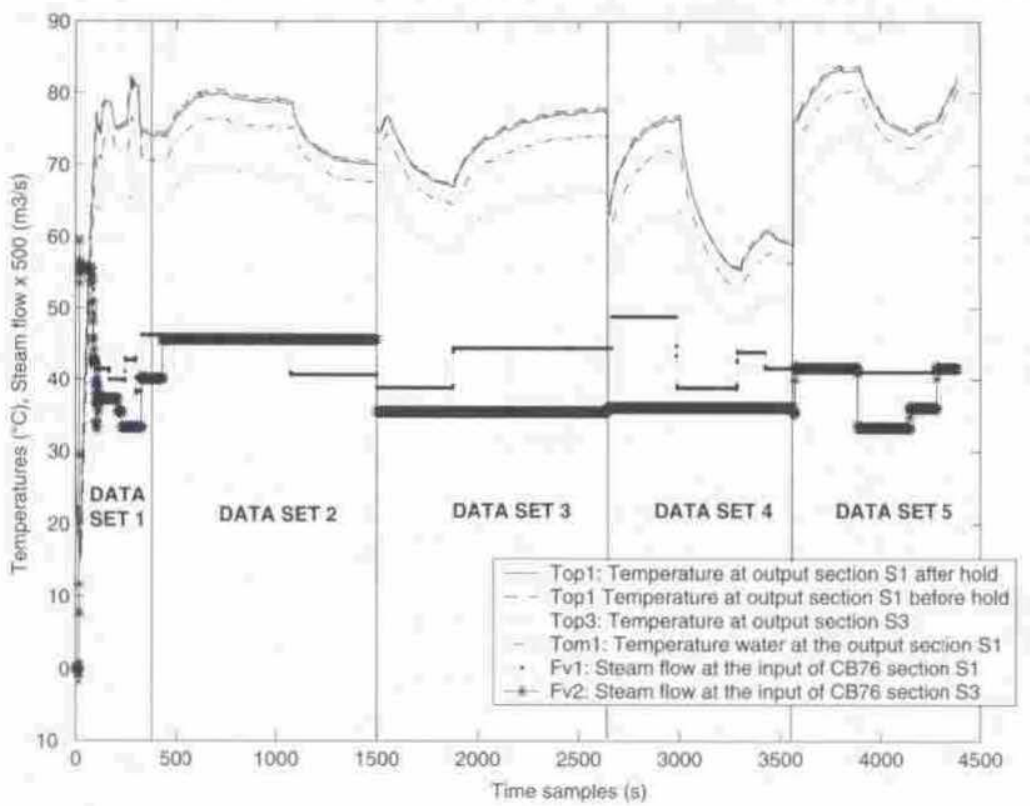

Fig. 5. Test protocols and plant response.

dimension of the BHE and PHE and the steady state responses of each section [2]. Subsequently, parameters were fine tuned on dynamical plant data. In order to produce a model most relevant around the normal plant operating point (including a pasteurisation temperature of $72-75^{\circ} \mathrm{C}$ ) data set 1 was excluded from the tuning and validation stages, due to extremely large temperature excursion evident during startup. Following fine tuning, the two sub-model responses are given in Figures 6 and 7 for pasteurisation and separation respectively. It can be seen from the figures that both sub-models behave "accurately" to the given test protocol with a Mean Absolute Error (MAE) of $0.6349^{\circ} \mathrm{C}$ and $1.4368^{\circ} \mathrm{C}$ for the pasteurisation and separation subsystems, respectively.

Note that the integrated model has been highly tuned in order to better match the process output in data set three (Figs, 6 and 7), as it is in the expected operative temperature range. The MAEs for set three are, $0.3328^{\circ} \mathrm{C}$ and $0.4201^{\circ} \mathrm{C}$ for pasteurisation and separation sub-models respectively. The lower and upper bounds of the plant response taking into consideration the uncertainty of the temperature sensors (i.e., $\pm 0.80^{\circ} \mathrm{C}[23]$ ) are plotted in Figure 8 . We can then see that both model responses lie almost always between the sensor error boundaries, which makes any further model improvement unnecessary. Results are summarised in Table 1, where model parameter values ( $\tau$ 's and $\lambda$ 's) are made available. 


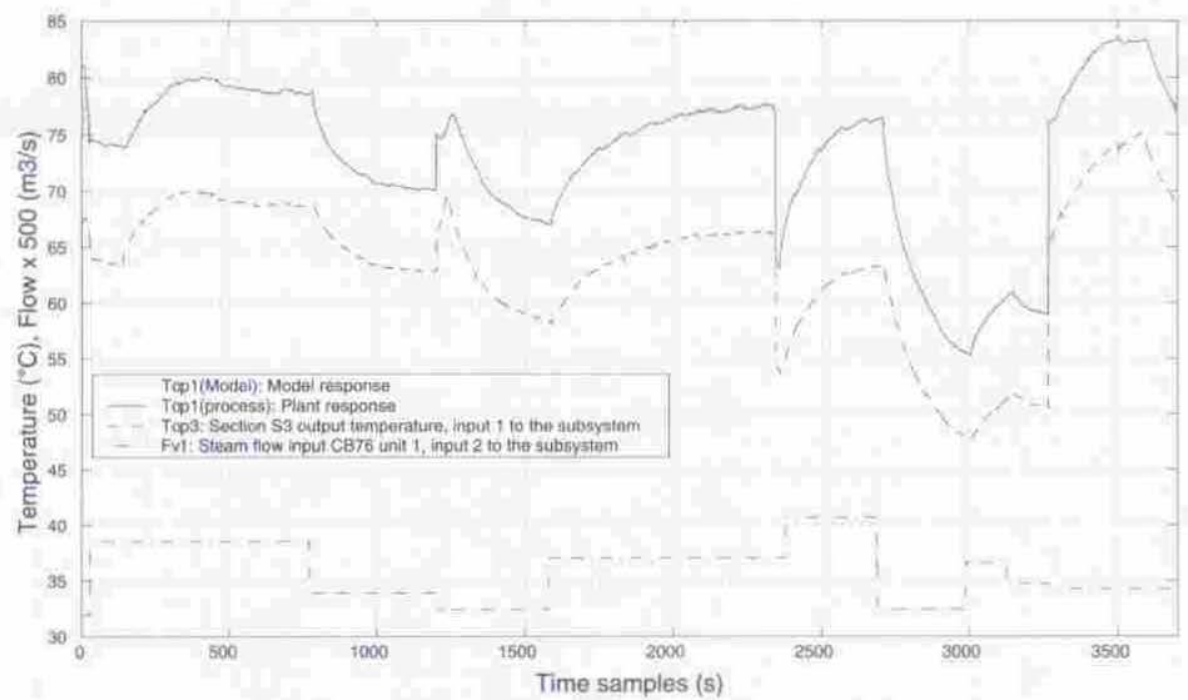

Fig. 6. Pasteurisation sub-model response for data sets 2 to 5.

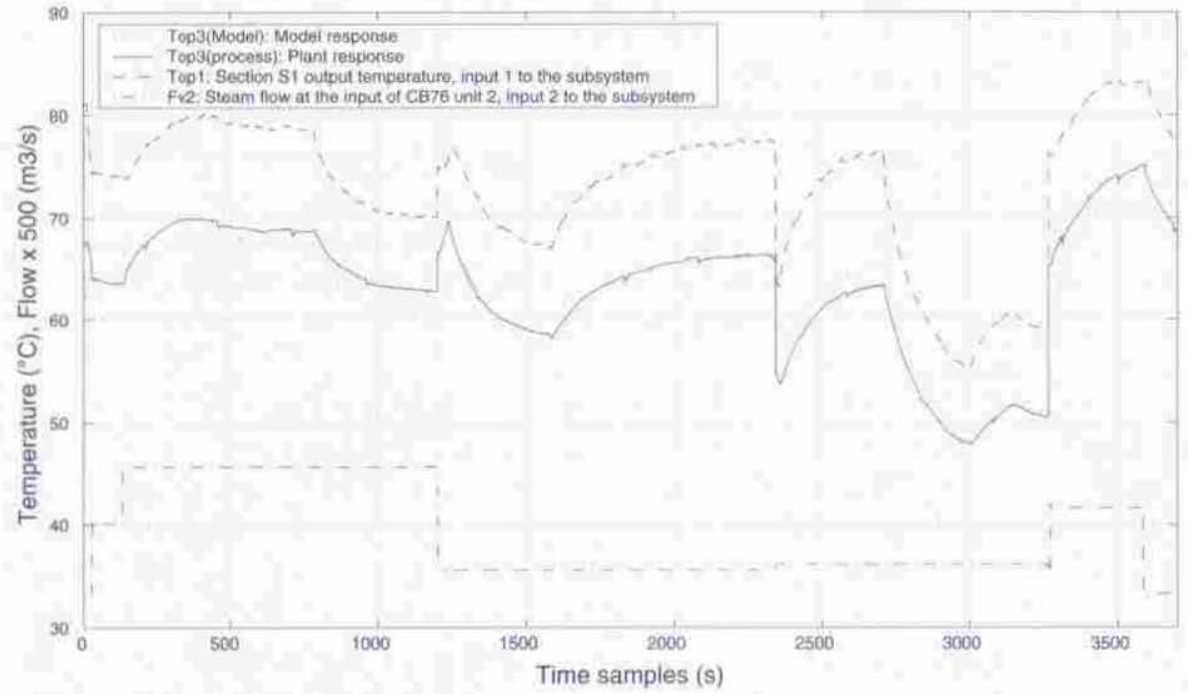

Fig. 7. Separation sub-model response for data sets 2 to 5 . 


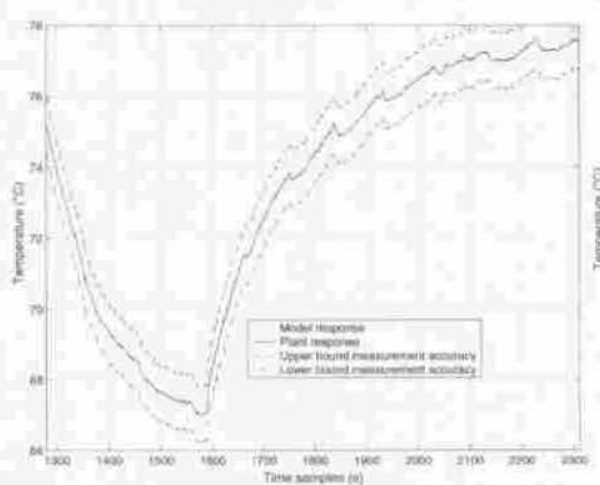

(a) Pasteurisation sub-model

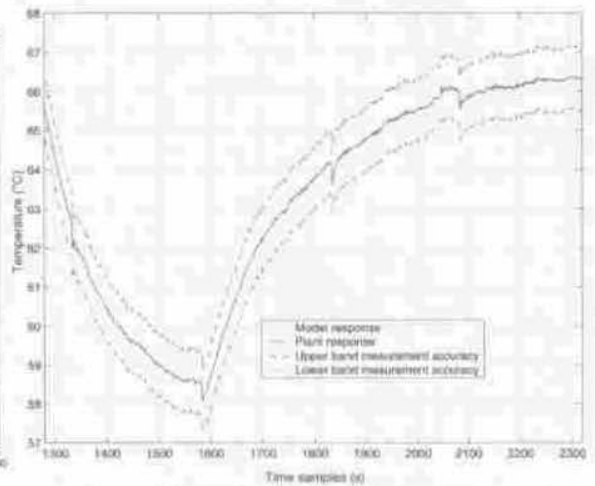

(b) Separation sub-moilel

Fig. 8. Model response for data set 3.

Table 1. Tuning and validation results.

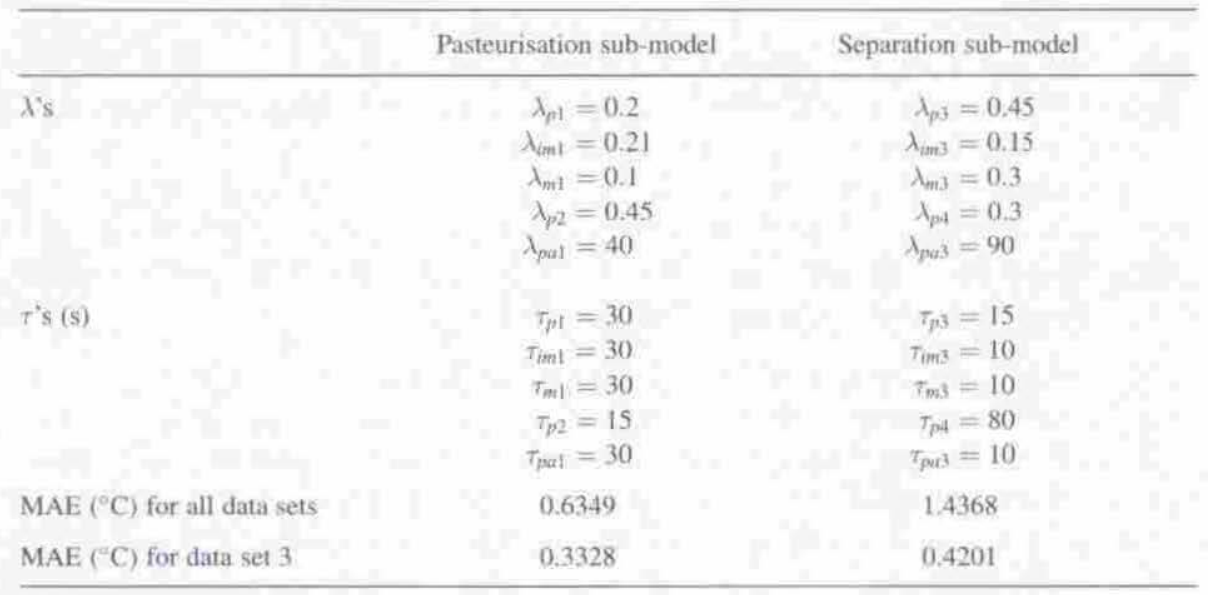

\section{USE OF THE MODEL IN A MODEL PREDICTIVE CONTROL STRATEGY}

Predictive control theory, in general, achieves process regulation by specifying the desired plant output at a particular instance or instances in the future and then calculating the controller action which minimises the predicted error in following a reference trajectory. The configuration of an MPC strategy is shown in Figure 9.

There is a wealth of material in the literature describing the state-of-the-art in MPC. The excellent texts by Soeterboek [25], Camacho [26] and Maciejowski [27] 


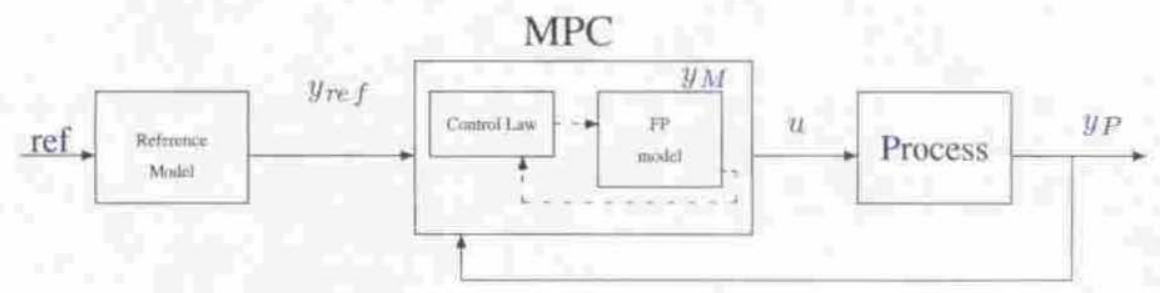

Fig. 9. MPC block diagram description.

provide a coverage of developments in the field from late 80 s to date, while the paper by Pannocchia et al. [28] show the extent to which the field has progressed in the immediate past, demonstrating an algorithm which allow constrained predictive control with dynamic input constraints.

MPC can use a variety of model types, both linear and nonlinear, as an internal model. These include FP models (as described in this paper), linear model types (e.g., the CARIMA model used in GPC [29]) and nonlinear neural network based [30, 31] or fuzzy rule based [32] models. In particular, the paper by Skrjanc and Matko [33] is noteworthy, since it deals with modelling and control of a heat exchanger, while a paper by Ibarrola et al. [34] also deals with predictive control of a pasteuriser, but with a Wiener model using Dynamic Matrix Control (DMC) [35].

In contrast to this paper, which adheres to a FP approach, both of the aforementioned papers utilise models derived from plant data. While it can be a more onerous task, there are a number of advantages in adopting a FP approach, rather than a data-based modelling methodology, including:

- True insight into the system dynamics is gained. where dynamical effects can be traced to specific system components,

- The FP model can easily accommodate changes in the system configuration through adjustment of the appropriate system parameter (for example changes to the number of plates employed in the heat exchanger or changes in the product or heating medium characteristics), while data-based models must be recalculated from scratch,

- FP models produce a global system description, while data-based models are only valid for the range of data used in the determination of the model.

MPC is widely used in industry $[1,36]$ as it usually takes into account any time delay or non-minimum phase effects, as well as any process constraints.

In this section simulation results of a predictive functional controller (PFC) [10] for the pasteurisation sub-model, are shown in Figure 10. The full derivation of the control law is detailed in $[21,38]$.

It can be seen that the controller performs very well, principally due to the power of the prediction given by the embedded internal model. This demonstrates the 


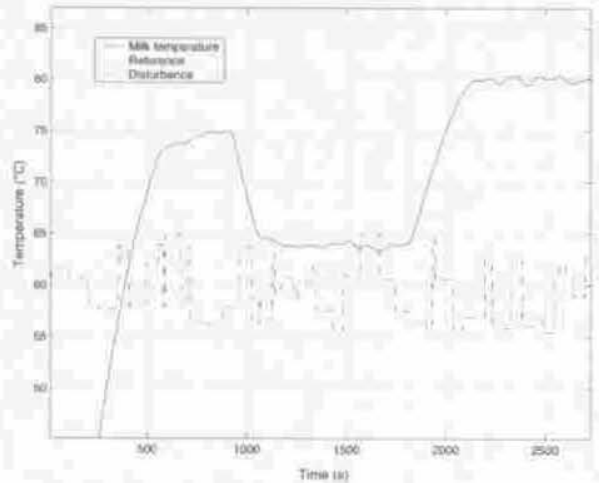

(a) Output product temperature $T_{\text {ep } 1}$

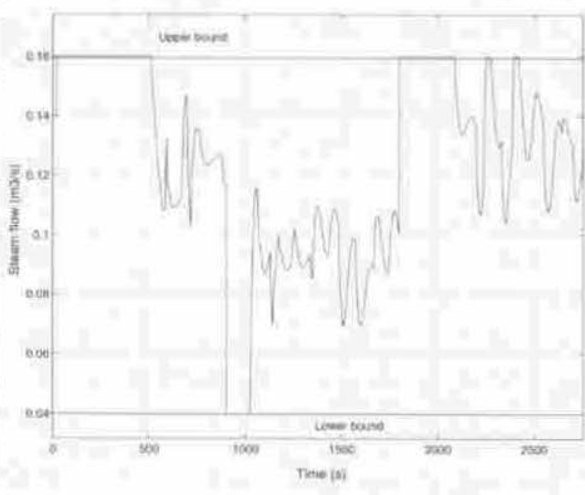

(b) Manipulated variable $F_{v 1}$

Fig. 10. PFC response with the FP model embedded.

importance of an accurate (and computationally compact) mathematical model of the process, which is the main focus of this paper.

Figure 10(a) shows how the temperature tightly follows the reference without over shooting, where the manipulated variable, in this case a steam flow $F_{y 1}$ injected to BHEI, is nicely shaped (no strong oscillations occurring) and is kept within constraints when the setpoint is reached. Figure 10(b).

\section{CONCLUSIONS}

The model established in Section 3.2 and validated in Section 6, gives a good prediction of the plant output temperatures, at least around the operating point of $72^{\circ} \mathrm{C}$. It can be seen, in Figure 8, that the model's output temperatures lies between the plant output measurement uncertainty bounds, given by the accuracy of the temperature sensors. Any further model improvement will not be justified without fitting more accurate sensors.

The modelling approach documented in Section 3.2 can be considered as a generic approach to liquid-to-liquid heat exchange modelling. A compact model for countercurrent heat exchange within a plate heat exchanger can be described by the differential equation expressed in Equation (20) and repeated in what follows in generic form for completeness:

$$
\tau \frac{d T_{o p}(t)}{d t}+T_{o p}(t)=\lambda T_{i p}(t)+(1-\lambda) T_{i m}(t)
$$

where the $\tau$ and $\lambda$ are the only parameters to identify. 
The generic model for fluid to fluid heat exchange, given in Equation (33), follows the convexity theorem by Richalet in [39], since the output product temperature is always convex between the input temperature of the product and medium. $\lambda$, the convexity parameter, is always contained between the values of 0 and 1 .

\section{REFERENCES}

1. Qin, S.J. and Badgwell, T.A.: An Overview of Industrial Model Predictive Control Technology. Chemical Process Control, AIChe Symposium Series. In: J. Kantor, C. Garcia and B. Carnahan (eds.): New York, 1997. pp. 232-256.

2. Alpha Laval: Clip 10-RM Mamual. Tetra Pak, Lund, Sweden. 1995.

3. Bylund, G.: Dairy Processing Handbook. Tetra Pak, Lund, Sweden, 1995.

4. Cooper, A and Usher, J.D.: Plate Heat Exchangers. In: Heat Exchanger Design Handbook. Hemisphere Publication Corporation, Vol. 3, No. 3.7. 1983.

5. Shah, R.K. and Focke, W.W.: Plate Heat Exchangers and Their Design Theory. Heat Transfer Equipement Design. New York, Hemisphere Publication Corporation, 1988.

6. Thonon, B.: Etude et optimisation de la distribution du fluide dans un echangeur de chaleur a plaques. $\mathrm{Ph} . \mathrm{D}$. Thesis, University of Nancy, France, 1991.

7. Thonon, B.: Les Echangeurs a Plagues 10 ans de Recherches - Partie 1 ecoulement et transfer de chaleur en simple et double phase. Rev. Gen. Thermique 34(397) (1995), pp. 77-90.

8. Leuliet, J.C.: Comportement hydraulique et thermique des échangeur á plaques traitant des pmoduits newtonien. Ph.D. Thesis, University of Nancy I, France, 1988.

9. Vidil, R., Ratel, G. and Grillot, J.M.: Thermal Hydraulic Performance of Plate and Frame Heat Exchangers - The CEPAJ Software, Design and Operation of Heat Exchangers. Springer Verlag, Berlin. 1992 ,

10. Thonon, B. and Mercier, P: Les Echangeurs a Plaques 10 ans de Recherches - Partie II Dimensionement et mauvaise distribution. Rev: Gen. Thermique 35 (1996), pp. 561-568.

11. Edwards, M.F., Ellis, D.L. and Amoie-Foumeny, T: The Flow Distribution in Plate Heat Exchangers, in: IChemE Symposium Series First UK Conference, Vol. 88, 1984, pp. 1289-1302.

12. Bassiouny, M.K. and Martin, H.: Flow Distribution and Pressure Drop in Plate Heat Exchangers Parts 1 and II. Chem. Eng. Sci. 39 (1984), pp. 317-330.

13. Hassler. L.E., Wadekar, V.V. and Clarke, R.H.: Flow Distribution Effects in Plate and Frame Heat Exchangers. In: Proceedings of the First European Conference on Thermal Science IChemE, Vol, 129, 1992

14. Wolf, J.: Plate Heat Exchanger. Int. J. Heat Mass Trans. 7 (1964), pp. $901-919$.

15. Zaleski, T: Chem. Eng. 39(7/8) (1984), pp. 1251-1260.

16. Morano, J.J. and Jechura, J.L.: Analysis of Plate Heat Exchangers. A/Che Symposium Series on Heat Transfer, Denver, 1985.

17. Lakshmanan, C.C. and Potter, O.W.: Dynamic Simulation of a Plate Heat Exchanger. Int. J. Heat Mass Trans. 33(5) (1990), pp. 995-1002.

18. Roetzel, W. and Das, S.K.: Hyperbolic Axial Dispersion Model: Concept and its Application to a Plate Heat Exchanger. Int. I. Heat Mass Trans, 38(16) (1995), pp. 3065-3067.

19. Das, S.K. and Roetzel, W.: Dynamic Analysis of Plate Heat Exchangers With Dispersion in Both Fluids. Int. J. Heat Mass Trans. 38 (1995), pp. 1127-1140.

20. Kays, W.M. and Crawford, M.E.: Comection Heat and Mass Transfer. McGraw-Hill Series in Mechanical Engineering, McGraw-Hill, New York, 1980.

21. Khadir, M.T: Modelling and Predictive Control of a Milk Pasteurisation Plant. Ph.D. Thesis. Deptartment of Electronic Engineering, National University of Ireland, Maynooth, Ireland, 2002. 
22. Higgins, J.R.: Sampling Theory in Fourier and Signal Analysis: Foundations. Oxford University Press, New York, 1996.

23. Richalet, J.: Pratique de Tidentification, 2nd edition. Hermes, Paris, 1998.

24. Alpha Laval: Technical Manual: Temperature Transmitter for Mounting in Sensor Pt-100. Tetra Pak. Lund, Sweden, 1998.

25. Soeterboek, R.: Predictive Contmol-A Unified Approach. International Series in System and Control Engineering. Prentice-Hall, Engelewood Cliffs, NJ, 1992.

26. Camacho, E.F. and Bordons, C.: Model Predictive Control. Springer-Verlag. London, 2000.

27. Maciejowski, J.M.: Predictive Control With Constraints. Pearson Education Limited, England, 2002.

28. Pannocchia, G., Wright, S.J. and Rawlings, J.B.: Existence and Computation of Infinite Horizon Model Predictive Control With Active Steady-State Input Constraints. IEEE Trams. Automatic Contr $48(6)$ (2003), pp. 1002-1006.

29. Clarke, D.W., Mohtadi, C and Tuffs, P.S.: Generalised Predictive Control - Part L. The Basic Algorithm. Automatica 23(2) (1987), pp. 137-148.

30. Renotte, C., Vande Wouwer, A. and Remy, M.: Neural Modelling and Control of a Heat Exehanger Based on SPSA Techniques. In: Proceedings of the American Control Conference, Chicago, Illinois, 2000, pp. 3299-3303.

31. Nørgaard, M., Ravn, O., Poulsen, N.K. and Hansen, L.K.: Neural Networks for Modelling and Control of Dynamic Systems. Springer-Verlag, London, 2000.

32. Lepetic, M., Skrjanc, L., Chiacchiarini, H.G. and Matko, D.: Predictive Control Based ob Fuzzy Model: A Case study. In: EEE International Fuzzy Systems Conference Proceedings, Melboume, 2001.

33. Skrjanc, 1. and Matko, D.: Predictive Functional Control Based on Fuzzy Model for Heat-Exchanger Pilot Plant, IEEE Trans. Fuzzy Syst. 8(6) (2000), pp. 705-712.

34. Ibarrola. J.J., Sandoval, J.M., Garcia-Sanz, M. and Pinzolas, M.: Predictive Control of a High Temperature-Short Time Pasteurisation Process. Contr. Eng. Pract. 10(7) (2002), pp. 713-725.

35. Cutler, C.R. and Ramaker, P.S.: Dynamic Matrix Control-A Computer Algorithm. In: Proceeding of the Joint Automatic Contml Conference, 1980.

36. Qin, S.J. and Badgwell, T.A.: In: F. Allgower, A. Zheng (eds.): An Overview of Nonlinear Modet Predictive Control Applications in Nonlinear Model Predictive Control. Birkhauser, Switzerland, 2000.

37. Richalet, J: La commande predictive. Techniques de l'Ingenieur Traite Mesure et Control. R7 423 (1998) pp. I-17.

38. Khadir. M.T, and Ringwood, J.V.: Higher Order Predictive Functional Control of a Milk Pasteurisation Plant. Contr. Eng. Pract. (2003) submitted for publication.

39. Richalet, J.: Industrial Applications of Predictive Control. In: Proceedings of the UKACC International Conference on Control. University of Cambridge, UK, 2000. 
Copyright of Mathematical \& Computer Modelling of Dynamical Systems is the property of Swets \& Zeitlinger, BV and its content may not be copied or emailed to multiple sites or posted to a listserv without the copyright holder's express written permission. However, users may print, download, or email articles for individual use. 